\title{
ATRIAL SEPTAL DEFECT
}

\author{
With special reference to the Electrocardiogram, the Pulmonary Artery Pressure \\ AND THE SECOND Heart Sound \\ - BY
}

\section{J. M. BARBER, O. MAGIDSON, AND PAUL WOOD}

From the Institute of Cardiology, London.

Received December 27, 1949

The primary purpose of this paper is to present certain highly characteristic features of atrial septal defect that are either insufficiently well known or poorly understood: these include particularly the electrocardiographic appearances, the pressures in the right side of the heart, and the nature and significance of the second heart sound.

It is generally agreed that the diagnosis of atrial septal defect is based mainly on the radiological findings. These have been well described by Assmann (1928), by Roesler (1934), and by Bedford, Papp, and Parkinson (1941), and are now well recognized-at least in advanced cases. The right auricle, right ventricle, and main pulmonary artery are dilated; the left and right branches of the pulmonary artery are unusually large and dense, and may pulsate with great vigour, while heavy vascular shadows mark the lung fields. In contrast, the aorta and left ventricle are hypoplasic (Fig. 1 and 2).

McGinn and White (1933) and more recently Burrett and White (1945) agree with the authors cited above that a purely clinical diagnosis cannot be made with confidence, although certain features are suggestive: these include partial or complete arachnodactyly, relatively good health in childhood and adolescence, the frequent association of mitral valve disease, the rarity of bacterial endocarditis, the not infrequent occurrence of auricular fibrillation, a thrusting cardiac impulse associated with gross right ventricular dominance, a pulmonary systolic murmur often accompanied by a thrill, accentuation of the pulmonary second sound, a pulmonary diastolic murmur, and an audible third heart sound. Electrocardiograms in atrial septal defect may show tall $\mathbf{P}$ waves, slight prolongation of the P-R interval, right ventricular dominance or right bundle branch block (Bedford, Papp, and Parkinson, 1941). Historical details will be given more fully later.

In recent years cardiac catheterization has been used with increasing frequency to prove the diagnosis, samples of blood obtained from the pulmonary artery, right ventricle, and right auricle containing appreciably more oxygen than samples from the venæ cavæ (Howarth et al., 1947).

Angiocardiography has proved less helpful, for the shunt is normally from left to right auricle, and the contrast medium becomes so diluted that it does not show up well after returning to the left auricle from the lungs. It is true that diodone may pass through the defect from right to left, owing to the high pressure generated in the right auricle by the force of the injection, but this does not distinguish atrial septal defect from patent foramen ovale.

\section{Cases Used for Present Study}

A series of 62 cases of atrial septal defect is presented. The electrocardiograms from 3 additional cases are considered. The diagnosis depended primarily upon the radiological features, but was confirmed in 21 by cardiac catheterization. No patient with persistent central cyanosis, advanced 


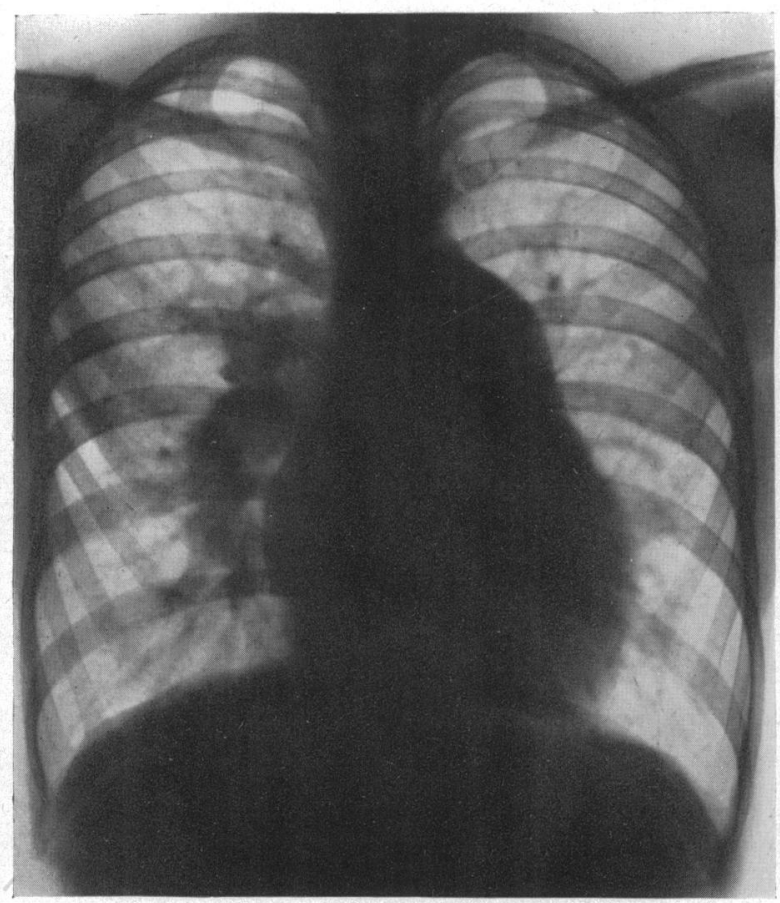

FIG. 1.-Skiagram of a case of atrial septal defect in a boy, aged 12, with gross enlargement of the pulmonary artery and its branches.

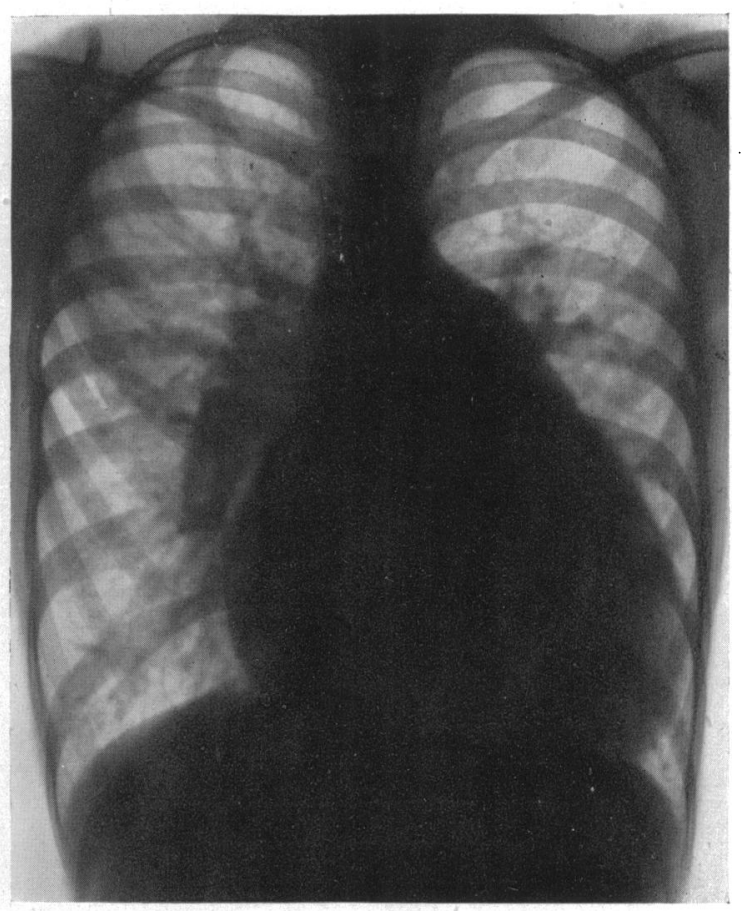

FIG. 2.-Skiagram of a case of A.S.D. in a girl, aged 7, showing gross enlargement of the heart shadow and marked engorgement of the pulmonary vascular tree (pulmonary plethora).

emphysema, or obvious mitral stenosis with dilatation of the left auricle was included. Care was also taken to exclude primary pulmonary hypertension, idiopathic dilatation of the pulmonary artery, simple pulmonary valvular stenosis, ventricular septal defect, and patent ductus-if necessary by cardiac catheterization.

\section{Clinical Features}

Age and sex. The distribution of cases over the various age groups is shown in Table I. The youngest patient was aged 5 years, the eldest 66 years. The high incidence of patients over 30 $(53 \%)$ is a unique feature of this form of congenital heart disease, and has been noted by all observers.

TABLE I

Age Incidence in 62 Clinical Cases of A.S.D.

\begin{tabular}{|c|c|c|c|c|c|c|c|c|c|c|}
\hline \multicolumn{3}{|c|}{$0-10$ years of age } & \multicolumn{2}{|l|}{. } & $\cdots$ & $\cdots$ & $\cdots$ & $\cdots$ & \multicolumn{2}{|c|}{5 cases } \\
\hline $11-20$ & ,, & , & . & . & . & . & . & . & 14 & , \\
\hline $21-30$ & , & , & . & . & . & . & .. & . & 10 & , \\
\hline $31-40$ & , & , & . & . & . & . & . & . & 13 & , \\
\hline $41-50$ & , & , & $\cdots$ & . & $\cdots$ & . & . & . & 11 & , \\
\hline $\begin{array}{r}51-60 \\
61\end{array}$ & ", & , & $\cdots$ & $\cdots$ & $\cdots$ & - & $\cdots$ & $\cdots$ & 6 & , \\
\hline $61-10$ & ," & ," & $\cdots$ & . & $\cdots$ & . & . & $\cdots$ & 3 & , \\
\hline
\end{tabular}

The preponderance of women is also well known, the ratio of females to males being $4: 1$ in the necropsy series reported by Bedford, Papp, and Parkinson (1941) and $3: 2$ in Roesler's series. In our 62 cases there were 43 females and 19 males, a ratio of over $2: 1$.

Symptoms and signs. The majority of patients were breathless on exertion (Table II) and seven, 
all over 40 years of age, had congestive heart failure. None had hæmoptysis. Of 13 cases entirely free from symptoms, 6 were vigorous school children under 16 years of age, 3 were active young women aged 22, 29, and 31,3 were boys aged 16,16, and 19, and the thirteenth was a male clerk aged 52. The physical signs are recorded in Table II.

TABLE II

Clinical Features of 62 Cases

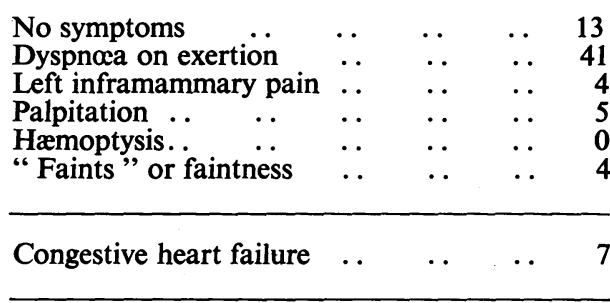

$\begin{array}{lllllllllll}\text { Hypertension } & \ldots & \ldots & \ldots & \ldots & 6\end{array}$ Cyanosis (all in congestive heart failure) 3

\begin{tabular}{|c|c|c|c|c|}
\hline \multicolumn{5}{|l|}{ Apex beat: } \\
\hline Displaced to the left & $\cdots$ & $\bullet$ & & \\
\hline able & & & & \\
\hline or forcible & . & . & & \\
\hline quality & & $\cdot$ & & \\
\hline Systolic thrill & & $\cdots$ & & \\
\hline \multicolumn{4}{|c|}{ Present or maximal at pulmonary area } & \\
\hline \multirow{2}{*}{\multicolumn{4}{|c|}{$\begin{array}{llll}\text { Systolic murmur } & \ldots & \ldots & \end{array}$}} & \\
\hline & & & & \\
\hline \multicolumn{2}{|c|}{ Pulmonary diastolic murmur } & . & & \\
\hline Mitral diastolic murmur & & & & \\
\hline \multicolumn{4}{|c|}{ Basal second sound widely split (grade 3 ) } & \\
\hline \multirow{2}{*}{\multicolumn{2}{|c|}{$\begin{array}{l}\text { Basal second sound loud } \\
\text { Audible third heart sound }\end{array}$}} & . & & \\
\hline & & $\bullet$ & & \\
\hline
\end{tabular}

Appearance. Under-development, frailness, the gracile habitus, arachnodactyly, high arched palate, and præcordial bulge have all been described as characteristic. One or more of these features were observed in a number of our cases, especially high arched palate and pigeon chest; but as their absence was rarely recorded in the notes, we are unable to tabulate their incidence.

Blood pressure. This was usually normal, but was raised in 6 cases, 2 of which had congestive heart failure.

Pulse. The rhythm was regular in 55 patients: auricular fibrillation occurred in six (aged 43-62), five of whom had congestive heart failure; flutter was recorded in one (aged 63) also in failure. Three of those with auricular fibrillation had a mitral diastolic murmur. The pulse was noticeably small in many, but was often normal.

Cyanosis. Cyanosis was observed in three patients, all of whom had congestive failure. In one of them the arterial oxygen saturation fell to 70 per cent on one occasion. There was no instance of clubbing of the fingers.

Cardiac impulse. It was Roesler (1934) who first emphasized the fact that a well circumscribed powerful thrust at the apex beat in the presence of gross right ventricular dominance was not only characteristic of atrial septal defect, but occurred in no other condition. We observed this type of cardiac impulse in several of our cases, and have come to regard it as evidence of a hyperkinetic right ventricle-a vigorously acting chamber with a greatly increased stroke volume. We prefer to describe it as tumultuous, to distinguish it from the tap of mitral stenosis, from the sustained heave of left ventricular hypertrophy, and from the sharp thrust of thyrotoxicosis. It is not unlike the cardiac impulse in patent ductus (due to similar behaviour of the left ventricle) and probably very like that in pure beri-beri (Wenckebach, 1928). The most impressive example occurred in a man who was subsequently found to have a heart weighing $940 \mathrm{~g}$., enlargement being entirely right-sided. In two-thirds of our cases, however, the cardiac impulse was tapping.

The apex beat was usually displaced beyond the mid-clavicular line, and occasionally beyond the anterior axillary line.

Thrills. A systolic thrill was recorded over the outflow tract of the right ventricle in 16 cases, but could not always be detected at every examination. Occasionally, a systolic thrill was confined to the apex-possibly due to associated mitral valve disease.

\section{Heart Sounds}

Particular attention was paid to the second heart sound: it was widely split in 52 cases and noticeably accentuated in 27 cases. 
It is usually stated that accentuation and splitting of the pulmonary second sound is evidence of pulmonary hypertension. We feel that this belief needs revision. In the first place it is rarely possible to recognize a pulmonary or aortic second sound, but only a second heart sound. It is reasonable to assume that the major part of it is normally aortic, because the aortic pressure is so much higher than the pulmonary. Thus in certain cases of aortic stenosis, the second heart sound may be almost inaudible, whereas in Fallot's tetralogy it is frequently quite loud, though single: the aortic element is absent from the first, the pulmonary from the second.

We have made a special study of the second heart sound in children and adults of all ages. Some degree of splitting can be detected clinically in most normal subjects; there were no exceptions in 100 children examined, and few in adults.

Three grades of splitting may be recognized: in grade I two elements can only just be appreciated, and an inexperienced observer may not perceive more than one; in grade II the split cannot be doubted, but the elements are still close; in grade III there is conspicuous wide splitting which is certainly pathological. Splitting in normal children is usually grade II, in normal adults grades I or II. In atrial septal defect it is commonly grade III. In right bundle branch block it is also grade III.

Conditions that might be expected to cause slight delay in aortic valve closure, such as hypertension, may be associated with a single or almost single second heart sound, and splitting in left bundle branch block may be only grade I. On the other hand grade II splitting is common in mitral stenosis, and grade III splitting in any circumstances usually means right bundle branch block. This suggests that the aortic element normally precedes the pulmonary element, despite electrokymographic evidence that the right ventricle begins to contract before the left (Luisada and Fleischner, 1947).

TABLE III

Age of Patients with $A . S . D$. and a Loud Third Heart Sound

\begin{tabular}{c|c|c}
\hline Age in years & $\begin{array}{c}\text { No. of cases with loud } \\
\text { third heart sound }\end{array}$ & Total cases \\
\hline $0-10$ & 1 & 5 \\
$11-20$ & 7 & 14 \\
$21-30$ & 4 & 10 \\
$31-40$ & 4 & 13 \\
$41-50$ & 5 & 11 \\
$51-60$ & 2 & 6 \\
$61-70$ & 3 & 3 \\
\hline & 26 & 62 \\
\hline
\end{tabular}

The intensity of the second heart sound requires separate analysis. Accentuation may be due to increased intensity of either element, and it is only possible to tell which element when there is sufficiently wide splitting; however, the answer can usually be determined indirectly by considering the clinical circumstances. The intensity of the sounds appears to depend upon the pressures in the aorta and pulmonary artery, and upon the relationship of the pulmonary artery to the anterior chest wall.

In atrial septal defect the mean pressure in the right ventricle and pulmonary artery may be normal or little above normal in the presence of grade III splitting. It is therefore reasonable to attribute the split to right bundle branch block or to delay in the emptying time of an over-filled right ventricle. Increased intensity of the second element, when present, may be due to the proximity of the dilated pulmonary artery to the chest wall. An extremely loud pulmonary element, however, usually means pulmonary hypertension and does not favour A.S.D.

A third sound best heard at the apex or lower end of the sternum was noted in 26 instances. In 14 of these the patient was over the age of 30 years, and in 5 there was associated mitral stenosis (without. dilatation of the left auricle). The incidence of the third heart sound in relation to the age of the patient is presented in Table III. 
Murmurs. No case was seen without a cardiac murmur. A systolic murmur was heard in all, and was maximal over the pulmonary artery in 52 of them. An early diastolic murmur was heard down the left border of the sternum in 36 cases (Table IV). It was usually short and rather high pitched, and might only be heard on careful auscultation in a quiet room. Although presumably due to pulmonary incompetence, the murmur was not confined to cases with gross cardiac enlargement or to those with very large pulmonary arteries, but was noted as frequently in young patients with relatively slight radiological changes in whom the diagnosis was established with certainty only by means of cardiac catheterization. It is therefore regarded as an important sign of A.S.D.

A rumbling presystolic or mid-diastolic murmur was heard at the apex in 9 instances and was attributed to mitral stenosis (Lutembacher's syndrome). As previously stated, such cases were only included when there was no other evidence of mitral stenosis. In distinguishing clinically between A.S.D. and other anomalies resulting in an increased pulmonary blood flow, a mitral diastolic murmur does not help, for it is a common expression of turbulence at the mitral orifice in both patent ductus and ventricular septal defect. If the murmur is ever functional in A.S.D. it must arise at the site of the defect, not at the mitral valve, for the mitral blood flow is diminished rather than increased, and the left ventricle tends to be underfilled.

TABLE IV

Age of Patients with A.S.D. and a Pulmonary Diastolic Murmur

\begin{tabular}{c|c|c}
\hline Age in years & $\begin{array}{c}\text { No. of cases with } \\
\text { pulmonary diastolic } \\
\text { murmur }\end{array}$ & Total cases \\
\hline $0-10$ & 3 & 5 \\
$11-20$ & 10 & 14 \\
$21-30$ & 6 & 10 \\
$31-40$ & 8 & 13 \\
$41-50$ & 3 & 11 \\
$51-60$ & 3 & 6 \\
$61-70$ & 3 & 3 \\
\hline & 36 & 62 \\
\hline
\end{tabular}

Cardiac failure. Cardiac failure was seen in seven patients, all of whom were over 40 years of age (Table V). Five of them had auricular fibrillation, one had auricular flutter, and one normal sinus rhythm; while three presented clinical evidence of mitral stenosis. Reversal of the interatrial shunt, causing central cyanosis, was observed once (Case 30) with an arterial oxygen saturation of 70 per cent. Two other cases were cyanosed, but were not specially investigated in this respect.

TABLE V

Age of Cases of A.S.D. with Congestive Heart Failure

(At time of first admission with failure)

\begin{tabular}{|c|c|c|c|c|c|c|c|}
\hline \multirow{7}{*}{$\begin{array}{lr}\text { Case } 44 \\
\text { Case } 30 \\
\text { Case } 46 \\
\text { Case } 4 \\
\text { Case } 8 \\
\text { Case } 43 \\
\text { Case } 42\end{array}$} & & . & • & & \multicolumn{3}{|c|}{43 years of age } \\
\hline & . & . & . & . & 47 & ,, & ,, \\
\hline & . & . & . & . & 48 & , & , \\
\hline & . & . & . & . & 49 & , & ," \\
\hline & . & $\cdots$ & . & . & 50 & ,, & ," \\
\hline & $\cdots$ & $\cdots$ & - & $\cdots$ & 62 & ," & , \\
\hline & . & . & . & . & 63 & , & , \\
\hline
\end{tabular}

All the patients admitted with congestive heart failure, except one who died suddenly (Case 44), responded satisfactorily to the usual methods of treatment. 


\section{Cardiac Catheterization in Atrial Septal Defect}

Venous catheterization of the heart as an aid to the diagnosis of congenital heart disease is now an accepted and widely practised procedure. Its use in the diagnosis of A.S.D. has been mentioned by a number of authors, including Brannon et al. (1945), Dexter et al. (1947 a, b, c), Sosman et al. (1947), Howarth et al. (1947), and Bing et al. (1948).

Passage of a catheter from right to left auricle does not distinguish A.S.D. from patent foramen ovale; it is necessary to demonstrate an interatrial shunt from left to right. This is achieved by showing that samples of blood from the right auricle, right ventricle, and pulmonary artery are similar and contain appreciably more oxygen than samples from the venæ cavæ. The volume of the shunt may be calculated by subtracting the systemic blood flow from the pulmonary blood flow.

In this series the diagnosis of $A . S . D$. was confirmed by catheterization in twenty-one instances (Table VI). Samples from the chambers on the right side of the heart (R.A., R.V., and P.A.) were similar and showed an average oxygen unsaturation of $31 \mathrm{ml}$. per litre, compared with $62 \mathrm{ml}$. per litre in the superior vena cava. The difference was always well beyond the margin of technical error. Samples obtained from the left side of the heart in six instances were between 92 and 95 per cent saturated.

TABLE VI

Results of CARDiac CATHeterization

\begin{tabular}{|c|c|c|c|c|c|c|c|c|c|c|}
\hline \multirow{2}{*}{\multicolumn{2}{|c|}{ Case }} & & \multirow[b]{2}{*}{ Age } & \multicolumn{4}{|c|}{ Oxygen unsaturation $\mathrm{ml} /$ litre } & \multicolumn{3}{|c|}{$\begin{array}{l}\text { Mean pressure in } \mathrm{cm} \text {. saline } \\
\text { above sternal angle }\end{array}$} \\
\hline & & & & S.V.C. & R.A. & R.V. & P.A. & R.A. & R.V. & P.A. \\
\hline $\begin{array}{l}\text { C. } \\
\text { D.B. } \\
\text { J.I. } \\
\text { Mrs. D. } \\
\text { G.F. } \\
\text { A.W. } \\
\text { J.D. } \\
\text { U.M. } \\
\text { I.M. } \\
\text { F.K. } \\
\text { F.Mc. } \\
\text { E.H. } \\
\text { S.H. } \\
\text { J.H. } \\
\text { M.Mc. } \\
\text { P.H. } \\
\text { C.O. } \\
\text { B.T. } \\
\text { G.C. } \\
\text { M.L. } \\
\text { F.D. }\end{array}$ & 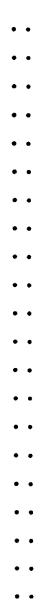 & $\begin{array}{l}\text { M. } \\
\text { F. } \\
\text { F. } \\
\text { F. } \\
\text { M. } \\
\text { F. } \\
\text { F. } \\
\text { F. } \\
\text { F. } \\
\text { M. } \\
\text { F. } \\
\text { F. } \\
\text { F. } \\
\text { F. } \\
\text { F. } \\
\text { F. } \\
\text { F. } \\
\text { F. } \\
\text { M. } \\
\text { F. } \\
\text { M. }\end{array}$ & $\begin{array}{l}17 \\
22 \\
12 \\
35 \\
16 \\
18 \\
18 \\
34 \\
21 \\
25 \\
25 \\
36 \\
16 \\
51 \\
25 \\
12 \\
31 \\
6 \frac{1}{2} \\
5 \\
14 \\
29\end{array}$ & $\begin{array}{l}60 \\
66 \\
55 \\
45 \\
56 \\
68 \\
63 \\
72 \\
70 \\
56 \\
68 \\
75 \\
67 \\
70 \\
75 \\
64 \\
55 \\
62 \\
42 \\
43 \\
60\end{array}$ & $\begin{array}{l}33 \\
28 \\
40 \\
30 \\
25 \\
28 \\
38 \\
32 \\
34 \\
26 \\
35 \\
35 \\
29 \\
32 \\
56 \\
35 \\
40 \\
20 \\
28 \\
25\end{array}$ & $\begin{array}{l}30 \\
40 \\
37 \\
31 \\
23 \\
28 \\
31 \\
26 \\
\\
33 \\
33 \\
29 \\
30 \\
60 \\
40 \\
- \\
18 \\
17 \\
16\end{array}$ & $\begin{array}{l}\bar{z} \\
\overline{28} \\
17 \\
27 \\
36 \\
30 \\
= \\
= \\
= \\
\overline{60} \\
= \\
\bar{z} \\
\overline{16}\end{array}$ & $\begin{array}{l}-1 \\
-5 \\
+3 \\
+1 \\
\pm 0 \\
-1 \\
-2 \\
- \\
-1 \\
\pm 0 \\
\pm 7 \\
+4 \\
-6 \\
+6 \\
\pm 0 \\
+2 \\
+1 \\
-4\end{array}$ & $\begin{array}{l}+16 \\
+19 \\
+6 \\
+14 \\
+14 \\
+15 \\
+16 \\
= \\
+20 \\
+15 \\
+9 \\
+19 \\
+15 \\
+20 \\
= \\
+12 \\
+10 \\
+8\end{array}$ & $\begin{array}{l}= \\
= \\
+8 \\
+19 \\
+18 \\
+22 \\
+22 \\
= \\
= \\
= \\
+11 \\
+18 \\
+16 \\
+10 \\
-\end{array}$ \\
\hline
\end{tabular}

Mean pressures in the right ventricle and pulmonary artery were but little raised, the range being $6-20 \mathrm{~cm}$. of saline $(4-15 \mathrm{~mm}$. Hg.) in the right ventricle and 8-22 cm. of saline $(6-16 \mathrm{~mm} . \mathrm{Hg}$.) in the pulmonary artery. The right auricular pressure was usually normal, but was raised in three instances.

The mean left auricular pressure, when obtained, was a little higher than the right, but rather less so than in controls with patent foramen ovale. The mean left ventricular pressure was between 48 and $72 \mathrm{~cm}$. of saline $(35-53 \mathrm{~mm} . \mathrm{Hg}$.) in the 5 cases in which this chamber was entered.

Simple calculations indicate that the pulmonary blood flow in A.S.D. averages about two and a half times the systemic flow, and is of the order of 10 litres a minute; thus the amount of blood shunted back to the right auricle is usually greater than the volume passed forwards to the left ventricle. The systemic flow is either normal or slightly reduced. 


\section{The EleCtrocardiogram}

The value of the electrocardiogram in A.S.D. has received increasing emphasis since Roesler's (1934) review. He had available only 7 electrocardiographic records from 62 cases. He noted right axis deviation, moderate in 4 cases and marked in 1, and stated that enormous dilatation of the right ventricle with moderate hypertrophy does not cause a high degree of right axis deviation. Leech (1935) described high $P$ waves with or without slight right ventricular preponderance. Bedford and Brown (1937) found right axis deviation often with inverted T waves in leads II and III and sometimes a widened QRS complex suggesting bundle branch block. Routier and de Balzac (1938) and Routier et al. (1940) stressed the diagnostic significance of the electrocardiogram ; of 300 cases of congenital heart disease the standard limb leads showed right bundle branch block (right B.B.Bl.) in 23; of these 20 proved to be cases of A.S.D.

Schnitker (1940) in his monograph considered that the absence of right axis deviation was no bar to the diagnosis of A.S.D.; "definite right ventricular preponderance" was seen in only 3 of 9 cases. He also commented on large $\mathrm{P}$ waves, occasional auricular fibrillation or flutter, abnormal notching of the QRS complex, and biphasic QRS complexes which Katz and Wachtel (1937) have described as pathognomonic of congenital heart disease.

Bedford, Papp, and Parkinson (1941) studied the electrocardiogram in detail in their series of 53 cases. They found auricular fibrillation in 6 ( 5 with mitral stenosis) and flutter in 1. Large high $P$ waves in one or more leads were seen in 15 cases; the auricular complex was large and bifid in three instances that were proved not to have mitral stenosis. They drew attention for the first time to the prolonged $\mathrm{P}-\mathrm{R}$ interval. In 19 cases it was 0.20 seconds or more and in one instance with partial right $B . B . B l$. it was 0.28 seconds. Right axis deviation occurred in 41 and left axis deviation in 2 cases. There were 5 records showing right $B . B . B l$., and 21 with a widened ventricular complex sometimes suggesting right $B . B . B l$. This type of graph was seen only twice in patients below the age of 30 and then with moderate cardiac enlargement. In one case right B.B.Bl. was seen to develop after 4 years observation. The authors were thus forced to agree with Routier et al. (1940), that right $B . B . B l$. was not an integral part of the congenital lesion but a sequel to it, and was closely related to right ventricular dilatation.

Burrett and White (1945) found right axis deviation, moderate or marked, in a high percentage and considered this very helpful in diagnosis. Taussig (1947) states that the electrocardiogram shows high $\mathrm{P}$ waves, frequently a prolonged $\mathrm{P}-\mathrm{R}$ interval, and not uncommonly widening and notching of the QRS complex. Right axis deviation is in her opinion the rule, but is not marked, because enlargement of the right ventricle is a combination of dilatation and hypertrophy.

Dry (1948) interpreted the electrocardiographic findings as indicating right ventricular strain, and noted impaired intraventricular conduction in 3 of his 5 cases. One of those with right B.B.Bl. was only 9 years old, and the author offered this as evidence against the view that the conduction defect was a sequel to, rather than a part of, the congenital lesion.

In the present series the initial electrocardiogram consisted of leads I, II, III, aVR, aVL, aVF, and V1, V3, and V5. About one-third of the cases also had leads from the right chest, V3R and V5R, and from the xiphisternum, VE (Wilson). All records were taken with the patient recumbent. The electrical axis was measured in the standard limb leads by the method of Carter et al. (1919). Axes between 0 and 90 were classed as normal. The electrocardiographic data so obtained in 65 cases are presented in Table VII.

$P$ wave. Conspicuous pulmonary or mitral $\mathrm{P}$ waves were not a feature of the A.S.D. electrocardiogram; thus, only two cases showed auricular complexes exceeding $2.5 \mathrm{~mm}$. in height, and in the majority of records the $\mathrm{P}$ waves were within normal limits. This point has not been sufficiently appreciated.

$P-R$ interval. There was a strong tendency for the $\mathrm{P}-\mathrm{R}$ interval to range around the upper limit of normal and in eleven cases it exceeded $0 \cdot 22$ seconds.

Electrical axis. Well marked left axis deviation was seen in 8 cases, but all had right B.B.Bl. 
TABLE VII

Electrocardiographic Data in 65 Cases of A.S.D.

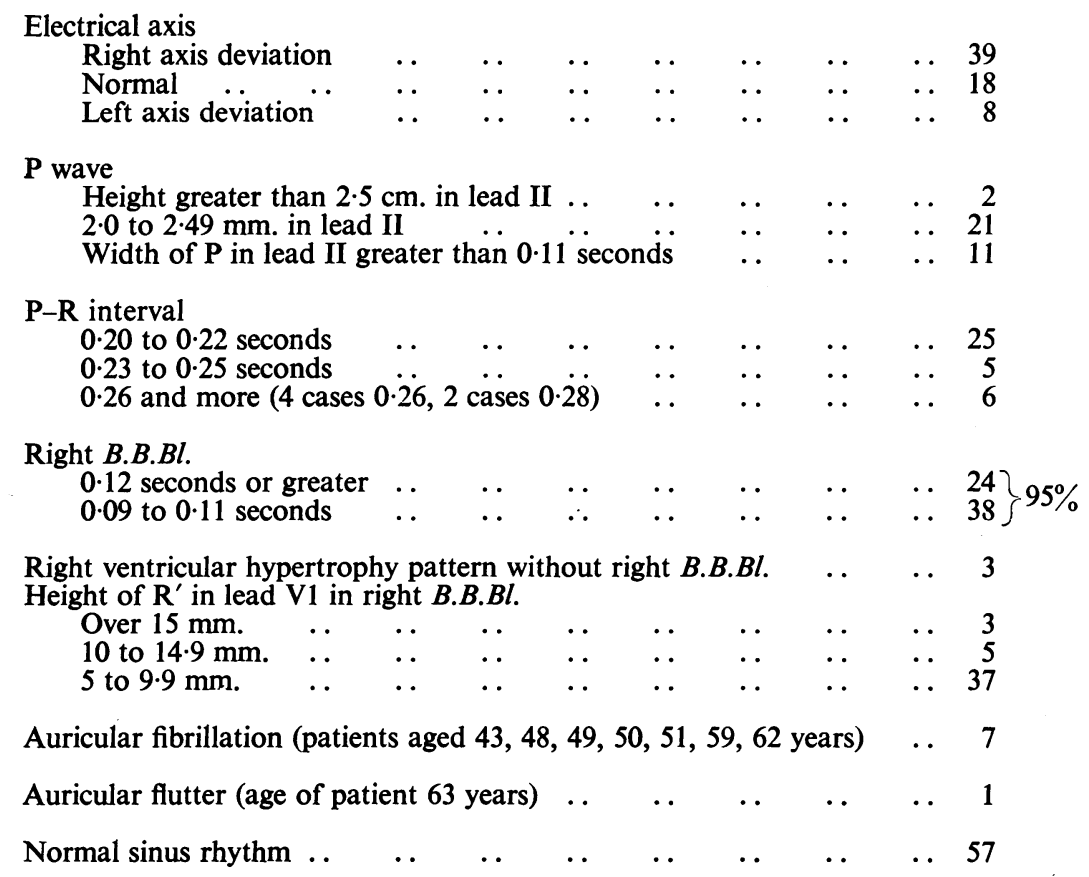

Similar curves were described by Bedford et al. (1941). Left axis shift was brought about in one of two ways. In 2 cases the heart was electrically vertical and deep S waves in lead V6 were transmitted to the left leg, and hence to standard lead III (Fig. 3). In the others the heart was semihorizontal with a shallow $S$ wave in leads from the left præcordium (Fig. 4); like Soulie and Joly (1948) we noted that in some of these cases VL and VF did not reflect unequivocal left or right ventricular potentials, and we were thus unable to determine the electrical position of the heart.

Right ventricular hypertrophy. There were only 3 cases with electrocardiograms showing dominant $\mathrm{R}$ waves without widening or notching in lead V1 (Fig. 5). These patients were young (aged 9, 12, and 16) and had little cardiac enlargement. In two the diagnosis of A.S.D. was confirmed by means of cardiac catheterization. It is certainly possible that right $B . B . B l$. may develop later in these cases, as the right ventricle enlarges. On the other hand, like Dry (1948), we have 8 cases showing right $B . B . B l$. in childhood (aged 5, 6, 7, 8, 11, 11, 12, and 13 years). Moreover, two of those with simple right ventricular dominance showed notching of the $R$ wave in lead V1 followed by an $\mathrm{S}$ wave. This may represent impaired conduction in the wall of the right ventricle.

Height of $R^{\prime}$ in lead VI. Wilson et al. (1947) state that conspicuous hypertrophy of the right ventricle combined with right $B . B . B l$. greatly increased the voltage of the secondary $R$ wave $\left(R^{\prime}\right)$ in leads from the right præcordium. It will be noted from Table VIII that the height of $R^{\prime}$ in lead $\mathrm{V}$ I varied considerably in this series, and we could not correlate it with the size of the right ventricle. In several patients with considerable right ventricular enlargement the amplitude of $R^{\prime}$ was only 2-3 mm. On the other hand, when right $B . B . B l$. is associated with pulmonary hypertension (and presumptive right ventricular hypertrophy) we agree that tall secondary $R$ waves are the rule (Fig. 6).

Right bundle branch block. The most significant electrocardiographic feature of this series was the remarkably high incidence of the right B.B.Bl. pattern: this occurred in 62 cases, or in 95 per cent. Multiple $\mathrm{V}$ leads undoubtedly aided its recognition. According to the criteria of Wilson et al. (1947), 38 of these cases had incomplete right B.B.Bl. (Fig. 7), QRS measuring only 0.09 to 


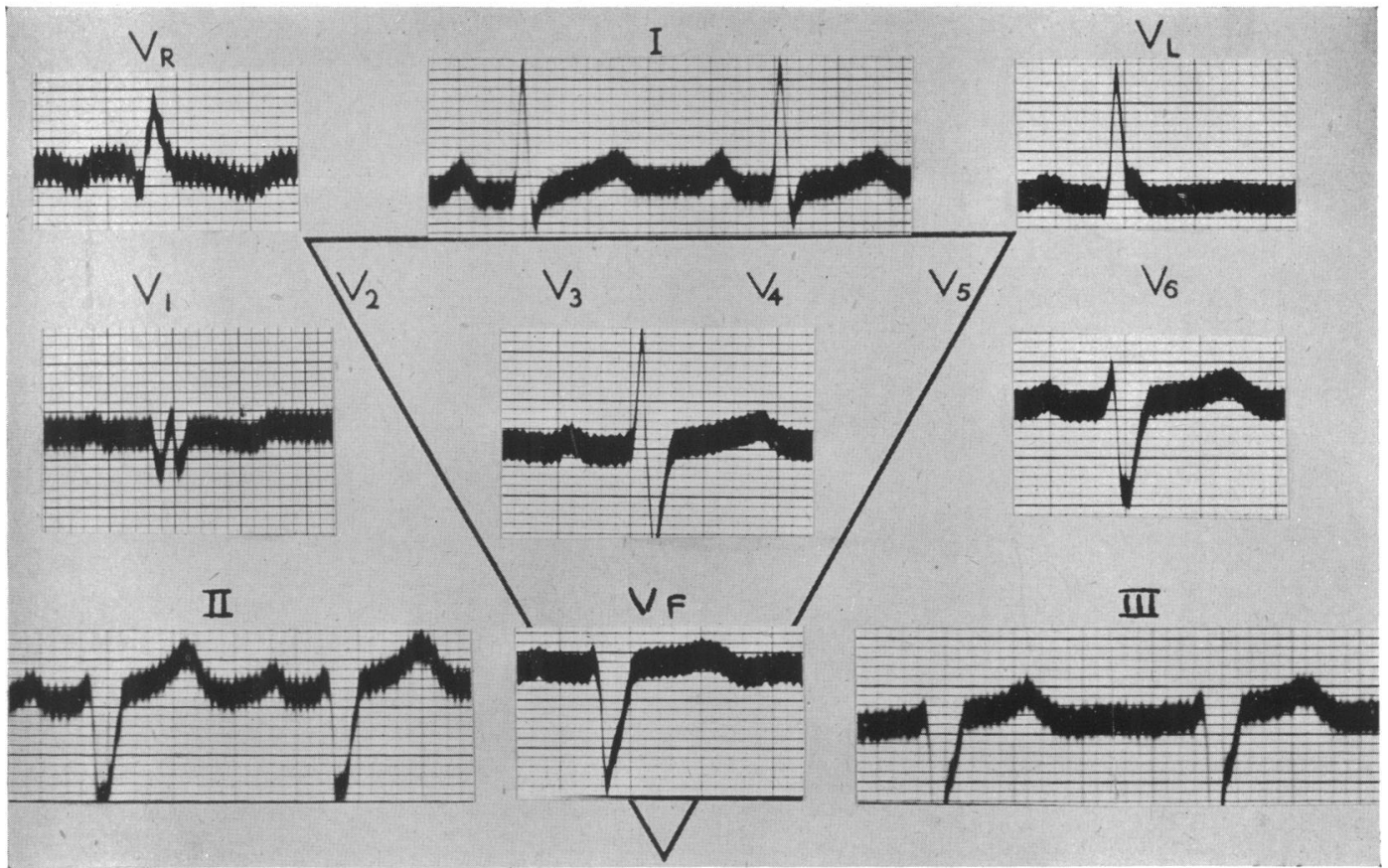

FIG. 3.-Electrocardiogram in a case of A.S.D., showing left axis deviation with right B.B.Bl. The heart is vertical, the left ventricular surface pattern seen in $\mathrm{V} 6$ being conducted to the left leg (VF).

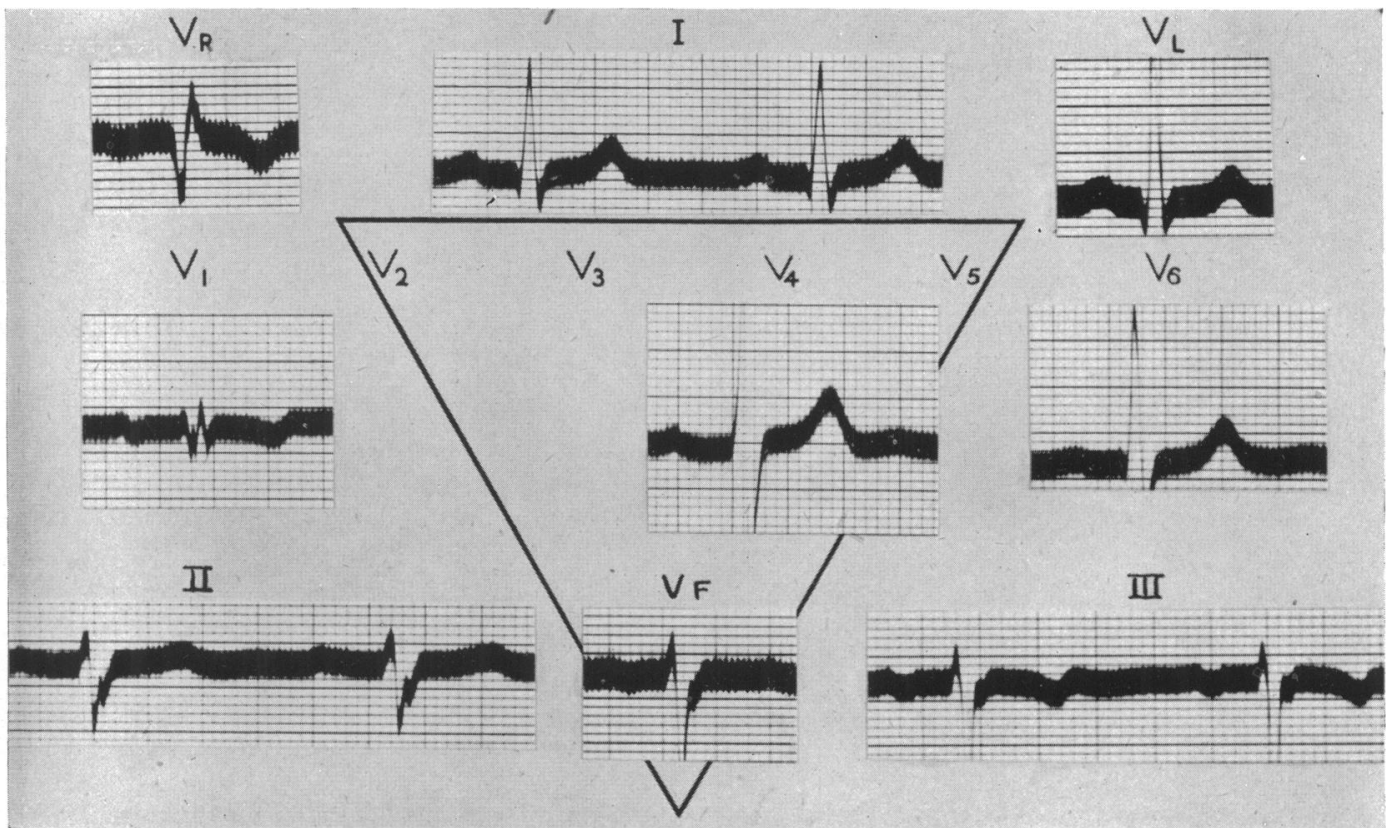

FIG. 4.-Electrocardiogram in a case of A.S.D., showing left axis deviation with right B.B.Bl. The electrical position of the heart is horizontal. The deep S wave in lead VF (and hence in leads II and III) is probably derived from lead V2 or V3. 


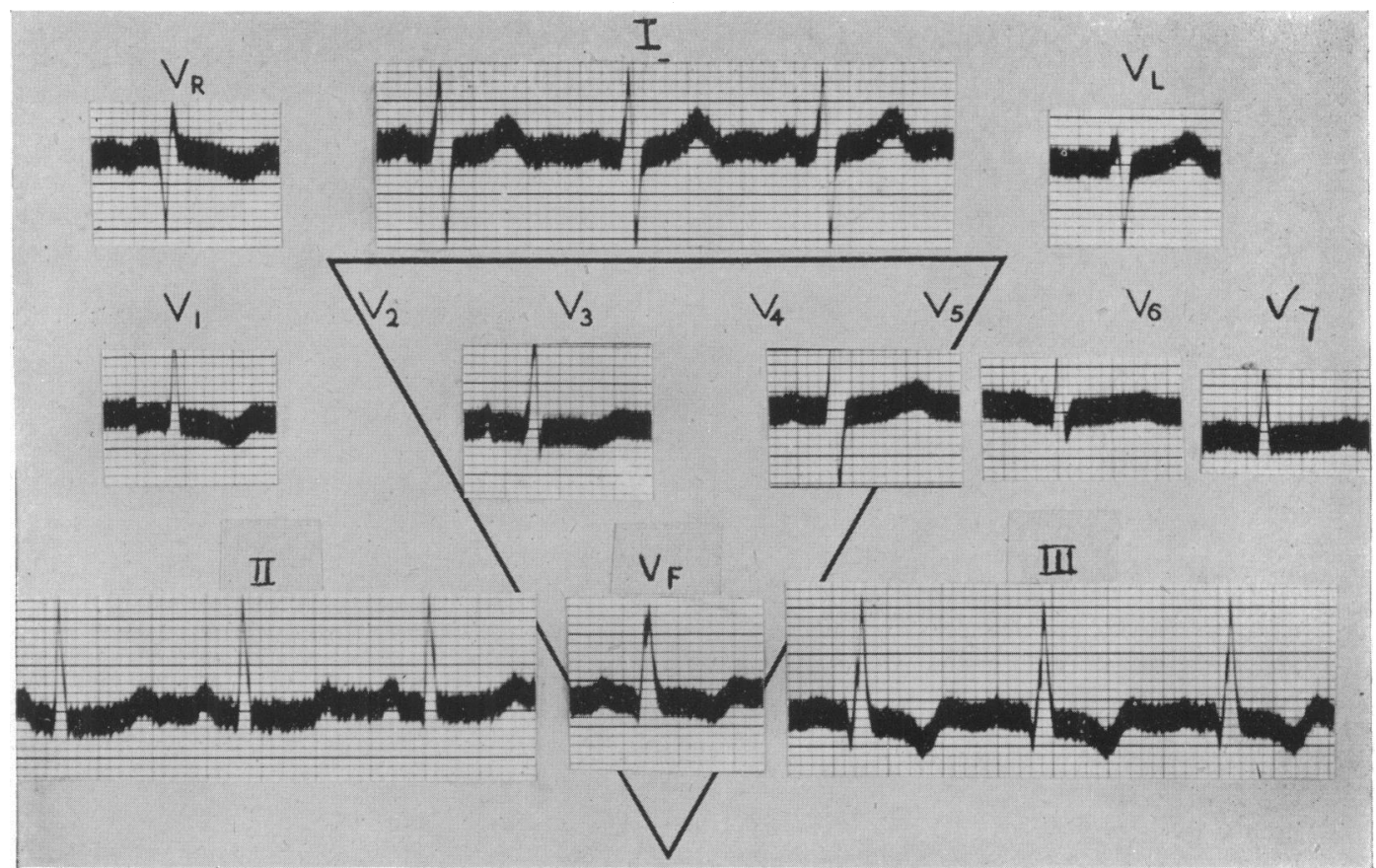

Fig. 5.-Electrocardiogram in a case of A.S.D., showing right ventricular dominance with no evidence of right $B . B . B l$.

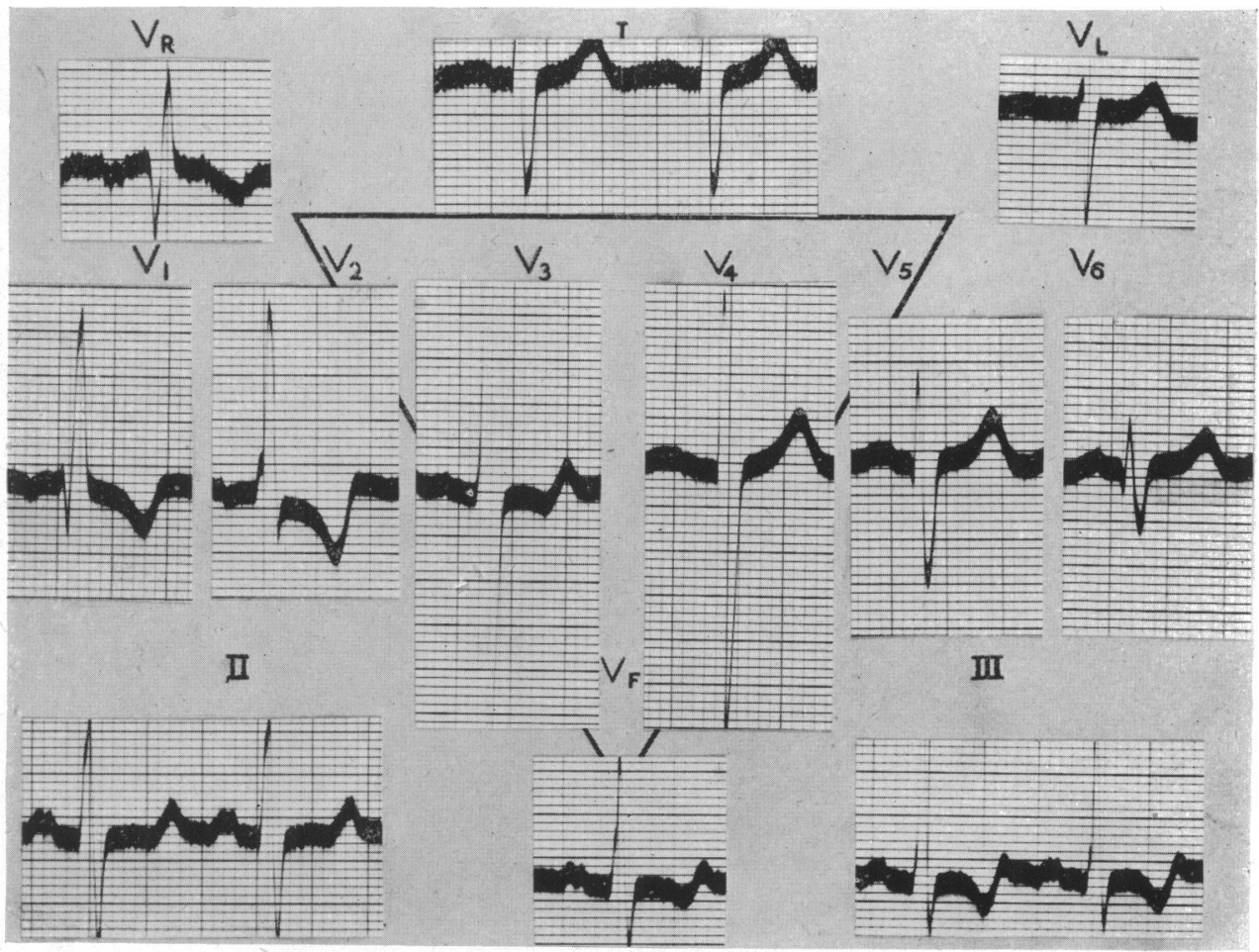

FIG. 6.-Electrocardiogram in a case of pulmonary hypertension with right $B . B . B l$., showing an unusually tall secondary $R$ wave in leads V1 and V2. 


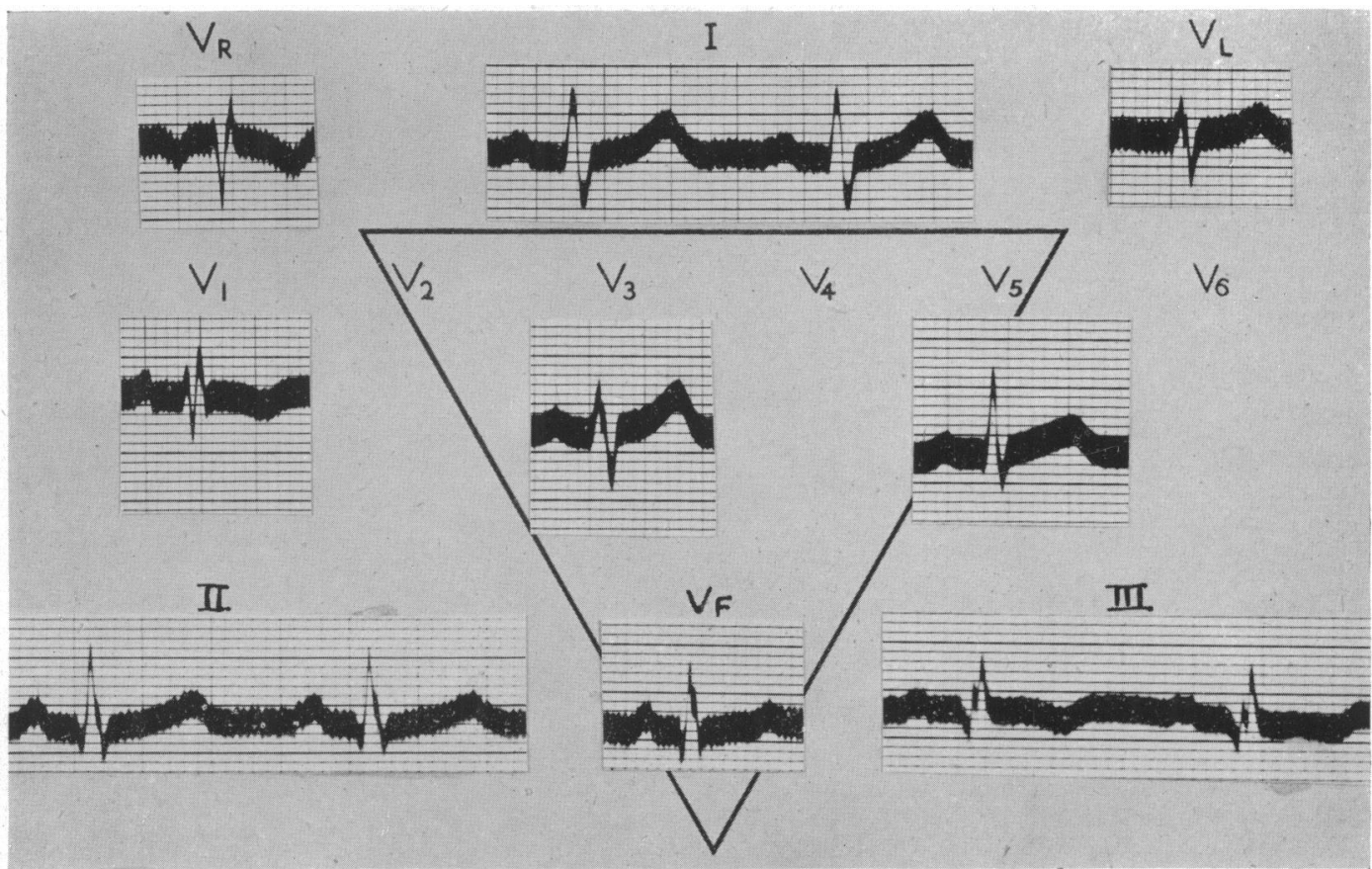

FIG. 7.-Electrocardiogram from a case of $A . S . D$., showing partial right $B . B . B I$.

$0 \cdot 11$ seconds, and there being a deep or wide $S$ wave in left ventricular surface leads or their counterparts (usually VL and standards lead I). The limb leads were rarely diagnostic. We relied mainly on finding a conspicuous secondary $R$ wave $\left(R^{\prime}\right)$ in leads $V I$ and $V E$, associated with slight or moderate widening of QRS (Fig. 8). The secondary $\mathrm{R}$ wave was often quite small in height and sometimes measured only $2 \mathrm{~mm}$. Occasionally it was followed by a small secondary $S$ wave $\left(\mathrm{S}^{\prime}\right)$, but this was never seen in lead V3R. In the majority of cases $R^{\prime}$ also occurred in lead V2 and often in lead V3 (Fig. 9). It is admitted that a small secondary $R$ wave may occur in lead V I in normal children and occasionally even in normal adults, but it is inconspicuous and QRS is not widened.

The right arm lead VR showed a QR complex with an inverted $\mathrm{T}$ wave in the majority; in a few there was a small initial positive deflection giving an $\mathrm{RSR}^{\prime}$ complex.

The diagnostic importance of partial or complete right $B . B . B l$. is further emphasized by its relative infrequency in mitral stenosis $(6 \%)$, tetralogy of Fallot $(10 \%)$, simple pulmonary stenosis $(20 \%)$, and pulmonary heart disease $(4 \%)$. The details of this comparative study are given in Table VIII.

TABLE VIII

Ventricular Complexes in Other Conditions Affecting the Right Side of the Heart

\begin{tabular}{|c|c|c|c|c|c|c|c|}
\hline & & & & $\begin{array}{l}\text { Mitral } \\
\text { stenosis }\end{array}$ & $\begin{array}{c}\text { Tetralogy of } \\
\text { Fallot }\end{array}$ & $\begin{array}{l}\text { Pulmonary } \\
\text { stenosis }\end{array}$ & $\begin{array}{c}\text { Chronic } \\
\text { pulmonary } \\
\text { heart disease }\end{array}$ \\
\hline $\begin{array}{l}\text { Number of cases } \\
\text { Ventricular complexes normal } \\
\text { Right ventricular hypertrophy } \\
\text { Right bundle branch block } \\
\text { Percentage with right } B . B . B l \text {. }\end{array}$ & $\begin{array}{l}\cdots \\
\cdots \\
\cdots \\
\cdots \\
\cdots\end{array}$ & $\begin{array}{l}\cdots \\
\cdots \\
\cdots \\
\cdots\end{array}$ & $\begin{array}{l}\cdots \\
\cdots \\
\cdots \\
\cdots\end{array}$ & $\begin{array}{r}64 \\
51 \\
9 \\
4 \\
6\end{array}$ & $\begin{array}{r}33 \\
0 \\
30 \\
3 \\
10\end{array}$ & $\begin{array}{r}10 \\
3 \\
5 \\
2 \\
20\end{array}$ & $\frac{100}{-}$ \\
\hline
\end{tabular}




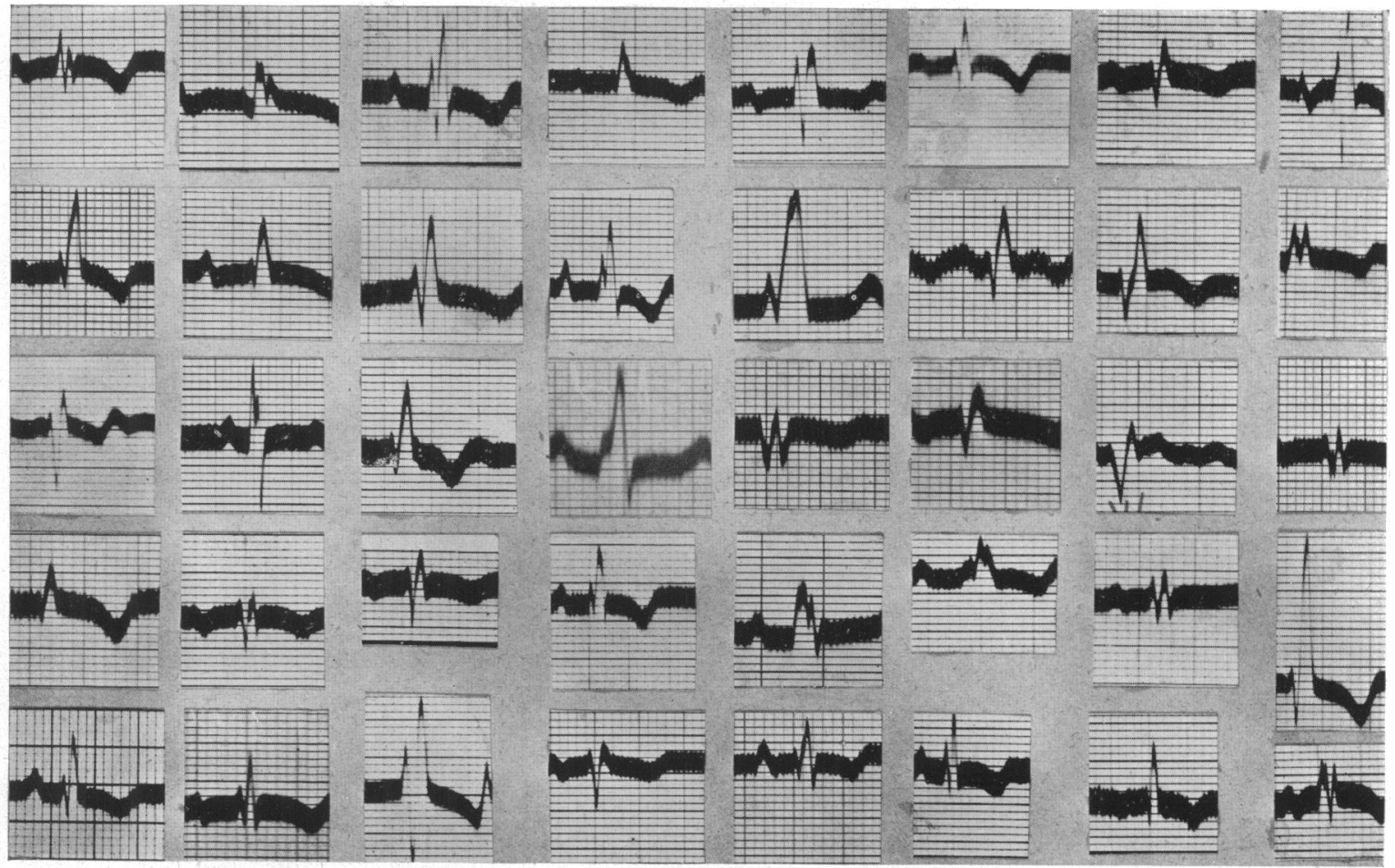

FIG. 8.-Electrocardiograms from lead V1 in 40 unselected cases of A.S.D. Nearly all show partial or complete right $\boldsymbol{B} . \boldsymbol{B} . \boldsymbol{B l}$.

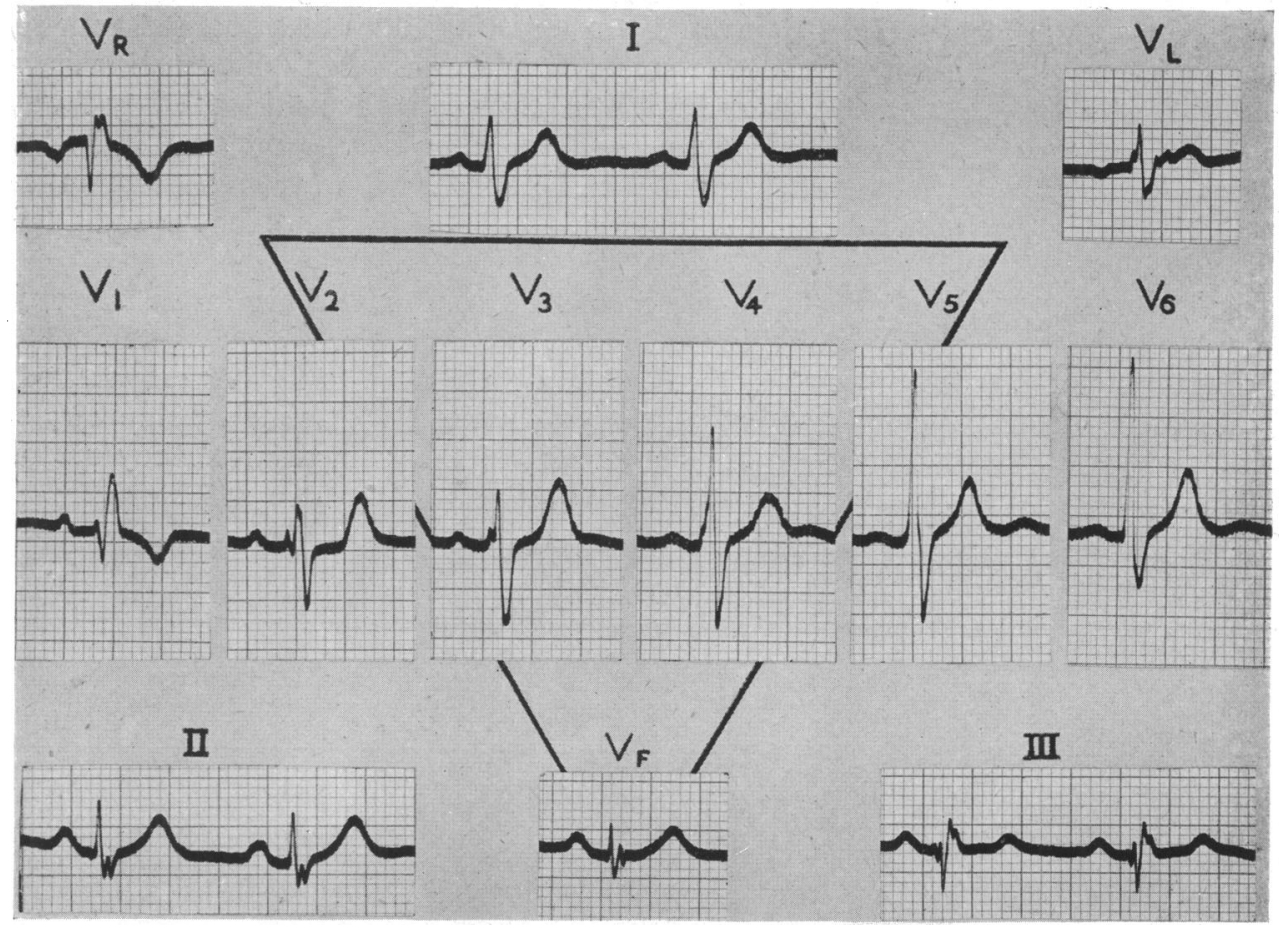

Fig. 9.-Typical example of right B.B.Bl. in a case of A.S.D. 
Discussion

Atrial septal defect is now widely recognized as the commonest single congenital cardiac anomaly and as one compatible with many years of active life. Its distinction from other forms of congenital heart disease is particularly important, because A.S.D. alone requires no protection from bacterial infection, and penicillin need not be given every time the patient has a sore throat or dental attention. Moreover, the rapid advance of cardiac surgery gives rise to some hope that A.S.D. may be repaired before long (Murray, 1948).

It is urged that a clinical diagnosis should be made with more confidence, the combination of a small or normal pulse, tapping or tumultuous cardiac impulse, lifting right ventricular outflow tract, pulmonary systolic murmur (with or without a thrill), pulmonary diastolic murmur, and widely split second heart sound in an acyanotic child or adult being practically diagnostic. Marked accentuation of the pulmonary element of the second heart sound favours pulmonary hypertension rather than A.S.D. As stated earlier in the paper, the presence of a mitral diastolic murmur does not favour A.S.D. (as Lutembacher's syndrome), for it is even more common in patent ductus and in $V . S . D$. with pulmonary plethora, as an expression of an increased mitral blood flow into a dilated left ventricle.

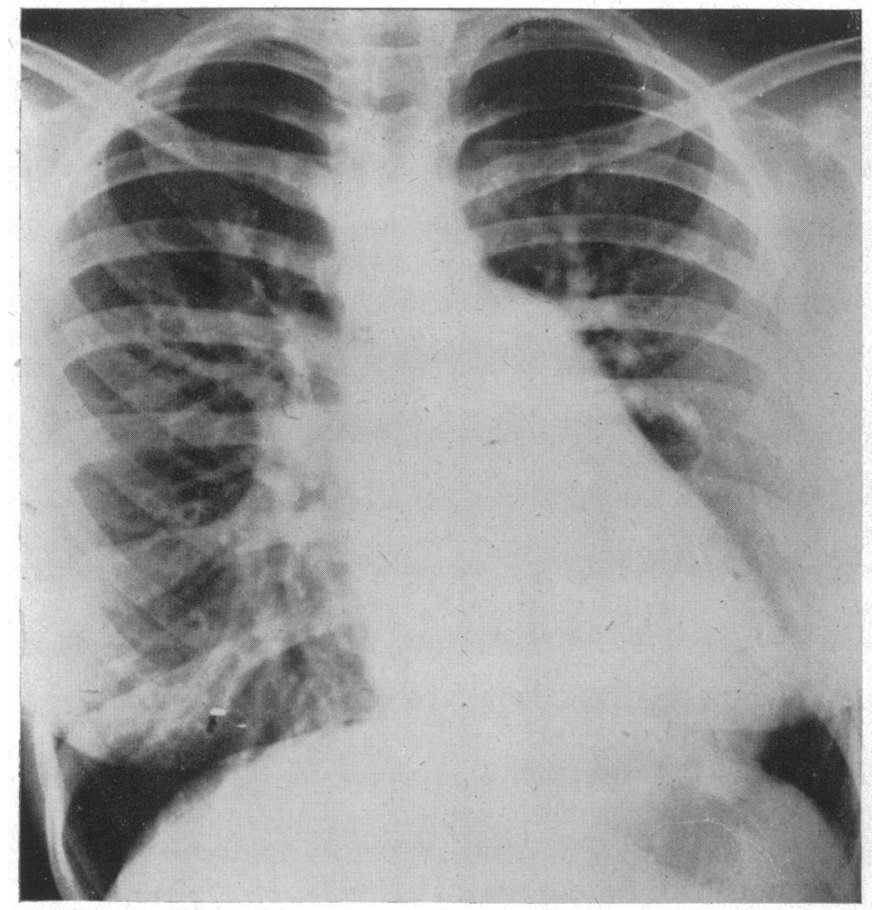

Fig. 10.-Skiagram showing dilatation of the pulmonary artery and pulmonary plethora in a case of ventricular septal defect. The left ventricle is enlarged, but this is not obvious in the view shown (i.e. it could be the right).

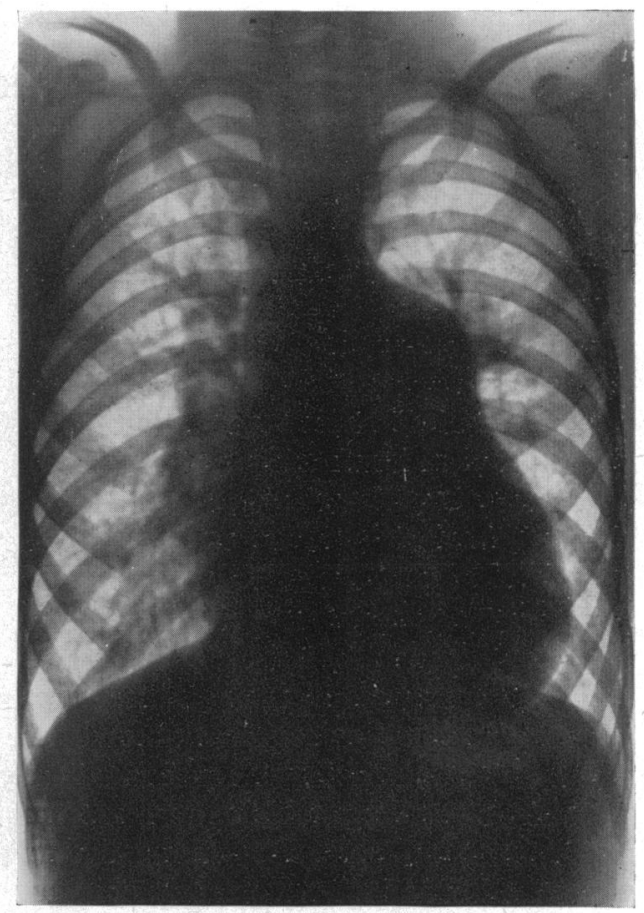

FIG. 11.-Skiagram showing dilatation of the pulmonary artery and pulmonary plethora in a case of patent ductus arteriosus. The left ventricle is enlarged.

The radiological appearances are of course very important, but they may not distinguish A.S.D. from V.S.D. (Fig. 10) or patent ductus (Fig. 11), and they are not always obvious in mild cases (Fig. 12 and 13). The chief value of fluoroscopy is to demonstrate pulmonary plethora and enlargement of the right ventricle, and it is true that A.S.D. can be distinguished in most cases in this way; but it is not always easy to be sure that enlargement is entirely right-sided, and skiagrams in the postero-anterior position may be particularly misleading in this respect, the appearances in A.S.D., V.S.D., and patent ductus being sometimes indistinguishable. 
The electrocardiogram provides extremely helpful information, for the diagnosis of A.S.D. is almost untenable in the absence of partial or complete right B.B.Bl. Again, under the clinical circumstances, the presence of right $B . B . B l$. at once makes $A . S . D$. the probable diagnosis, the chances being about ten to one in its favour. When partial right B.B.Bl. occurs in a case of V.S.D. or patent ductus, there is usually some evidence of left ventricular enlargement, particularly a deep $Q$ wave and tall $\mathrm{R}$ wave in left ventricular surface leads, and a relatively deep $\mathrm{S}$ wave in lead $\mathrm{V} 1$; occasionally, there is also depression of the S-T segment or even inversion of the T wave in leads V5 or 6. It is rare to meet obvious right $B . B . B l$. in these conditions. The diagnostic importance of wide splitting of the second heart sound is due entirely to its indicating right $B . B . B l$.

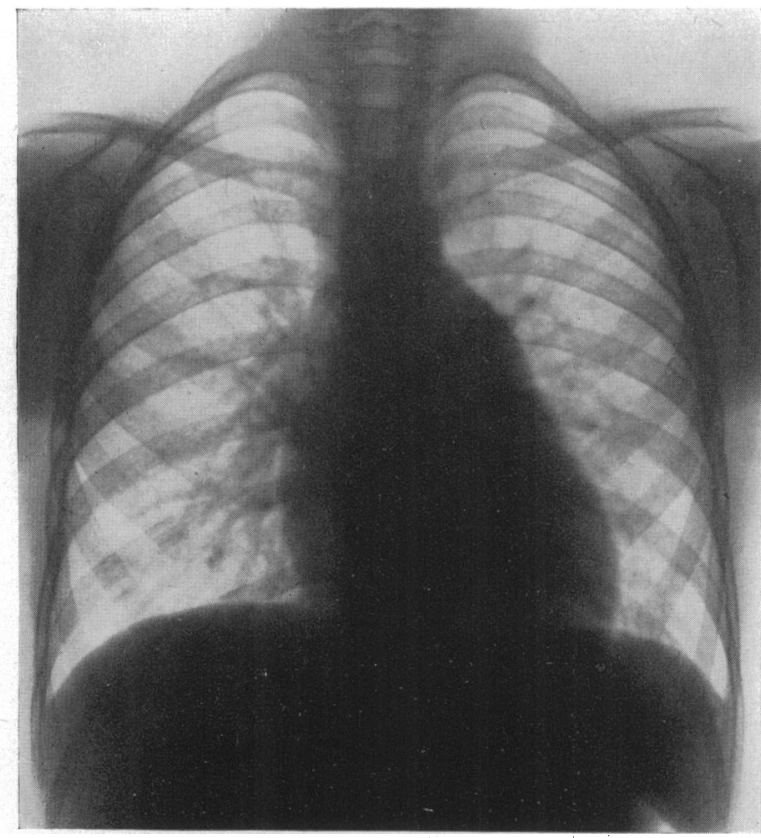

FIG. 12.-Skiagram in a relatively mild case of A.S.D. Diagnostic signs are present, but are not advanced.

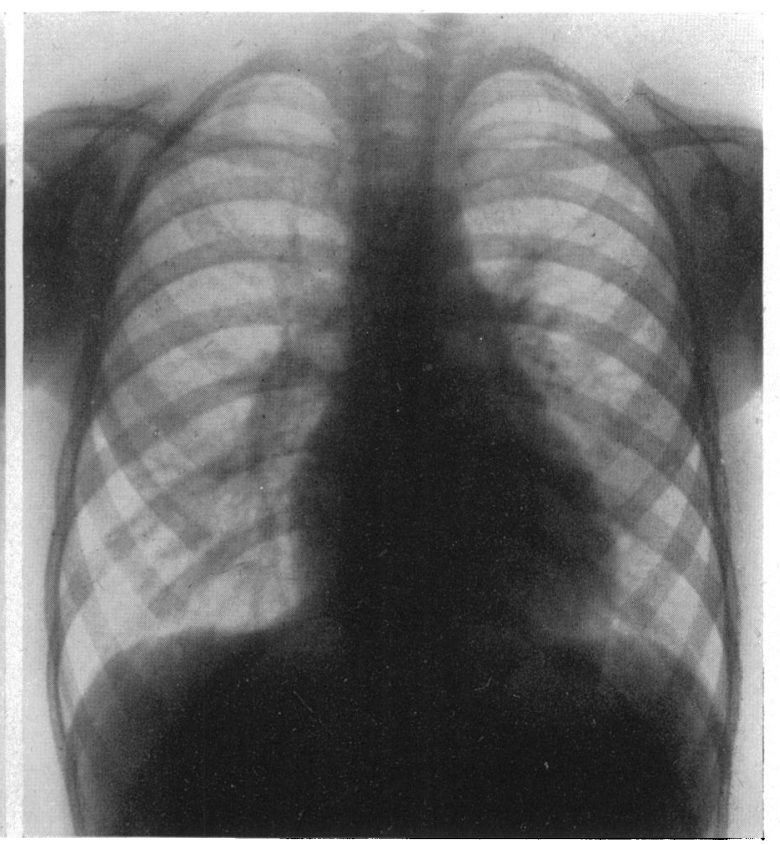

FiG. 13. -Skiagram from a relatively mild case of A.S.D., showing minimal changes.

The data presented in no way determine whether right $B . B . B l$. in atrial septal defect is caused by a local congenital or acquired lesion of the right bundle branch, or whether it results from dilatation of the right ventricle. There can be little doubt, however, that dilatation of a ventricle may produce the electrocardiographic pattern of homolateral bundle branch block both experimentally (Rasmussen, 1942) and clinically - in massive pulmonary embolism for instance. The discovery of delayed conduction in infancy or early childhood does not favour a congenital anomaly of the bundle in question, for dilatation of the right ventricle must occur as soon as the shunt operates.

The absence of prominent pulmonary $\mathbf{P}$ waves is interesting in view of the relatively low right ventricular pressures recorded in this series, and harmonizes with previous work suggesting that the tall spiked $P$ wave is indirectly related to a high right ventricular pressure (Wood, 1948).

In differential diagnosis the following rules have been found valuable.

1. A normal heart with a pulmonary systolic murmur, relatively conspicuous pulmonary artery, and grade II splitting of the second heart sound may suggest A.S.D., but may be distinguished by a normal electrocardiogram.

2. Idiopathic dilatation of the pulmonary artery with pulmonary incompetence may give rise to right $B . B . B l$., but may yet be recognized by the absence of radiological evidence of pulmonary plethora, dilatation being limited to the trunk or main branches of the pulmonary artery. 
3. Simple pulmonary valvular stenosis with dilatation of the pulmonary artery presents no problem, because the second heart sound is single.

4. Patent ductus arteriosus without a machinery murmur and perhaps with pulmonary incompetence is easily distinguished by the water hammer quality of the pulse.

5. V.S.D. with pulmonary plethora and with a high or unimpressive basal systolic murmur and thrill and partial right $B . B . B l$. may be very confusing, but may be recognized by electrocardiographic or radiological evidence (in the second oblique position) of left ventricular enlargement.

Cardiac catheterization offers convincing proof of A.S.D. except in rare late cases in which the shunt is reversed, and should be undertaken in all doubtful instances. The shunt is nearly always considerable, and averages about one and a half times the systemic blood flow, i.e. it is of the order of 6 to 7 litres a minute. The difference in the oxygen content between samples from the superior vena cava and samples from the right auricle, right ventricle, and pulmonary artery have always been well beyond the range of technical error or spontaneous variation. Another very constant finding has been the remarkable absence of pulmonary hypertension. That patients with A.S.D. may remain active and free from symptoms for so long emphasizes again the fact that the heart is less embarrassed by pumping an increased volume of blood than it is by pumping against increased resistance.

\section{SUMMARY AND CONCLUSION}

A series of 62 cases of atrial septal defect is presented.

A clinical diagnosis may be made in most instances if an acyanotic child or adult, with few if any symptoms, presents a small or normal peripheral pulse, tapping or tumultuous cardiac impulse, lifting right ventricular outflow tract, pulmonary systolic murmur with or without a thrill, pulmonary diastolic murmur, and wide splitting of the second heart sound.

Wide splitting of the second heart sound is attributed to right B.B.Bl. or to delay in the emptying time of an over-filled right ventricle, and is a far more important sign of A.S.D. than accentuation of the pulmonary second sound.

The electrocardiogram shows partial or complete right B.B.Bl. in 95 per cent of cases; indeed the diagnosis of A.S.D. is untenable in its absence, unless proof is obtained by means of cardiac catheterization.

A conspicuous $\mathrm{P}$ pulmonale is no part of the electrocardiographic pattern of A.S.D.

$\mathrm{X}$-ray appearances may be diagnostic of $A . S . D$. if evidence of pulmonary plethora can be shown to be associated with enlargement of the right ventricle only; but this is not always possible. Skiagrams in cases of V.S.D. or patent ductus present similar evidence of pulmonary plethora and can only be distinguished if enlargement of the left ventricle can be recognized with certainty.

The radiological changes in mild cases of A.S.D. in children may be scarcely beyond the limits of normal variation.

Cardiac catheterization was performed in 21 of the 62 cases of A.S.D. presented. Samples from the right auricle, right ventricle, and pulmonary artery were usually between 80 and 90 per cent saturated; samples from the venæ cavæ were normal (about $70 \%$ saturated.) The difference was always well beyond the limits of technical error or spontaneous variation. The pulmonary blood flow averaged about two and a half times the systemic flow.

Absence of pulmonary hypertension was constant and noteworthy. Obvious accentuation of the pulmonary element of the second heart sound does not favour a diagnosis of atrial septal defect.

We wish to thank the consulting staff of the National Heart Hospital for allowing us to investigate and present some of their cases; particularly Sir John Parkinson who also helped us in other ways. 


\section{REFERENCES}

Assmann, H. (1928). Die klinische Rontgendiagnostik der inneren erkrankengen. 4th ed. Leipzig.

Bedford, D. E., and Brown, J. W. (1937). Brit. Encycl. Med. Pract., Vol. 6. Butterworth \& Co., London.

, Papp, C., and Parkinson, J. (1941). Brit. Heart J., 3, 37.

Bing, R. J., Handelsman, J. C., and Campbell, J. A. (1948). Mod. Concept. Cardiovascular disease, $17,3$.

Brannon, E. S., Weens, H. S., Warren, J. V. (1945). Amer. J. med. Sci., 210, 480.

Burrett, J. B., and White, P. D. (1945). Ibid., 209, 355.

Carter, E. P., Richter, C. P., and Greene, C. A. (1919). Bull. Johns Hopkins Hosp., 30, 162.

Dexter, L. (1947). Radiology, 48, 45.

—, Haynes, F. W., Burnett, C. S., Eppinger, E. C., Sosman, M. C., and Evans, J. M. (1947). J. Clin. Invest., $26,561$. $-,-\frac{-}{\text { T. J }},-\frac{1}{1948}$, Siebel, R. E., and Evans, J. M. (1947). Ibid., 26, 547.

Dry, T. J. (1948). Med. Clin. North Amer., 32, 895.

Howarth, S., McMichael, J., and Sharpey-Schafer, E. P. (1947). Brit. Heart J., 9, 292.

Katz, L. N., and Wachtel, H. (1937). Amer. Heart J., 13, 202.

Leech, C. B. (1935). J. Paediat., 7, 802.

Luisada, A. A., and Fleischner, F. G. (1947). Proc. Soc. Exper. Biol. Med., 66, 436.

McGinn, S., and White, P. D. (1933). Amer. Heart J., 9, 1.

Murray, G. (1948). Ann. Surg., 128, 843.

Rasmussen, H. (1942). Acta Med. Scand., 110, 32.

Roesler, H. (1934). Arch. intern. Med., 54, 339.

Routier, D., Brumlik, J., Malinsky, A. (1940). Arch. Mal Caur., 33, 40.

, and de Balsac, H. (1938). Bull. Soc. Belge Cardiol., 5, 41.

Schnitker, M. A. (1940). The Electrocardiogram in Congenital Heart Disease, Cambridge Mass., Harvard University Press.

Sosman, M. C. (1947). Radiology, 48, 441.

Soulie, P., and Joly, F. (1948). Arch. Mal. Caur., 41, 130.

Taussig, H. B. (1947). Congenital Malformations of the Heart, Commonwealth Fund, New York.

Wenckebach, K. F. (1928). Lancet, 2, 265.

Wilson, F. N., Rosenbaum, F. F., and Johnston, F. D. (1947). Advances in Internal Medicine, Vol. 2, Interscience Publishers, Ltd., London.

Wood, P. H. (1948). Brit. Heart J., 10, 87. 